\title{
Espaços de risco à saúde na região Metropolitana do Rio de Janeiro: uma análise das trajetórias dos poluentes atmosféricos e da condição de vida da população
}

\section{Espacios de riesgo para la salud en la región Metropolitana de Río de Janeiro: un análisis de las trayectorias de los contaminantes del aire y las condiciones de vida de la población}

\author{
Heitor Soares de Farias ${ }^{\text {; }}$ Jorge Luis Fernandes de Oliveira ${ }^{2}$
}

\begin{abstract}
RESUMO
A tentativa de recuperação econômica do Estado do Rio de Janeiro fez com que o projeto de construção de uma rodovia fosse concretizado mais de 40 anos depois. Junto a ela vieram grandes empreendimentos, com forte potencial poluidor, capazes de atrair outras indústrias, promovendo uma reorganização espacial produtiva na região metropolitana do Estado do Rio de Janeiro. No entanto a Geografia da região, uma planície à beira-mar rodeada pela Serra do Mar, com 900 metros de altitude em média, dificulta a dispersão dos poluentes atmosféricos que ficam concentrados próximos à superfície na área mais densamente habitada do país. Assim, o objetivo deste trabalho é identificar os espaços de risco à saúde da região metropolitana do Rio de Janeiro, ou seja, as áreas que mais concentram poluentes atmosféricos e a população mais vulnerável aos efeitos desses poluentes. Como metodologia foram utilizados os modelos atmosféricos BRAMS e trajetórias cinemáticas 3D para observar a circulação de ventos e a dispersão de poluentes, respectivamente, subsidiando a construção de mapas com as áreas de potencial concentração dos mesmos. Postriormente foi mapeada a população mais vulnerável aos efeitos da poluição e o cruzamento desses dois mapas teve como resultado o mapeamento dos espaços de risco. A rodovia e os empreendimentos estão localizados em áreas onde a população apresenta piores condições de vida, parte deles em uma área já bastante poluída, podendo levá-los a desenvolver problemas respiratórios relacionados à má qualidade do ar.
\end{abstract}

Palavras-chave: modelos atmosféricos, poluição do ar, qualidade de Vida.

\section{RESUMEN}

El intento de recuperación económica en el Estado de Río de Janeiro a través de la construcción de una carretera generó la instalación de grandes empresas, la promoción de una reorganización espacial productiva en la región, como también un fuerte potencial contaminador. La geografía de la zona, una llanura costera junto a la Serra do Mar, con 900 metros de altura en promedio, impide la dispersión de contaminantes en el aire que se concentran cerca de la superficie en la zona más densamente poblada del país. El objetivo de este trabajo es identificar las zonas de riesgo para la salud del área metropolitana de Río de Janeiro, o las zonas que concentran más contaminantes del aire y los más vulnerables a los efectos de estos contaminantes. La metodología utilizo modelos atmosféricos y BRAMS 3D trayectorias cinemáticas para observar el movimiento de los vientos y la dispersión de contaminantes, respectivamente, permitiendo la construcción de mapas de concentración potencial de los mismos. Posteriormente fue mapeada la población más vulnerable a los efectos de la contaminación, de cuyo cruce de información se elaboró la cartografía de las zonas de riesgo. La carretera y las empresas se encuentran en zonas donde la población tiene peores condiciones de vida, algunos de ellos en una zona ya muy contaminado, pudiendo desarrollar problemas respiratorios relacionados a la mala calidad del aire.

Palabras clave: modelos atmosféricos, contaminación del aire, calidad de vida.

Recibido el 22 de septiembre de 2016; aceptado el 28 de noviembre de 2016.

\footnotetext{
1 Departamento de Geociências da Universidade Federal Rural do Rio de Janeiro - UFRRJ. Rodovia BR-465 km47, UFRRJ, Seropédica, Rio de Janeiro, Brasil. CEP: 23890-000. heisofa@gmail.com

2 Departamento de Geografia da Universidade Federal Fluminense - UFF, Brasil.
} 


\section{INTRODUÇÃO}

A região metropolitana do Rio de Janeiro (RMRJ) tem a qualidade do ar comprometida devido à presença da segunda maior concentração de indústrias, veículos e de outras fontes de poluentes atmosféricos. Entretanto, indiferente a essa realidade, uma parceria entre o governo federal e o governo estadual do Rio de Janeiro transformou o Arco Metropolitano (rodovia BR-493) em realidade.

A rodovia BR-493 foi criada para interligar os municípios da RMRJ às rodovias federais e facilitar o acesso ao Porto de Itaguaí, aumentando o fluxo de caminhões nesta região. Ademais, nas proximidades do Arco Metropolitano foram instaladas indústrias pesadas, como o Complexo Petroquímico do Rio de Janeiro (COMPERJ) na extrema zona oeste do Rio de Janeiro e a Companhia Siderúrgica do Atlântico (CSA), em Itaboraí. A expectativa é que outras indústrias de diferentes ramos sejam instaladas nas proximidades da rodovia, promovendo uma reorganização espacial produtiva no território do Estado do Rio de Janeiro (OLIVEIRA \& ROCHA, 2012). Os investimentos no setor industrial, apesar de dinamizarem a economia da região trarão sobrecarga de poluentes, deixando a população mais vulnerável aos problemas de saúde relacionados à qualidade do ar.

O relevo acidentado onde localiza-se a RMRJ, uma vasta planície à beira-mar com a presença de três grandes maciços circundada pela Serra do Mar, com altitude média de 900 metros, interfere no transporte de poluentes atmosféricos, formando áreas com distintas concentrações dos mesmos (OLIVEIRA, 2004), potencializando os problemas cardiorrespiratórios na população mais vulnerável aos efeitos dos poluentes. O risco potencial à saúde da população apresentado por essas indústrias está comprovado pelas multas aplicadas pelo Instituto Estadual do Ambiente do Rio de Janeiro (INEA) à CSA por lançar material particulado metálico, popularmente denominado de chuva de prata, sobre a população vizinha ao empreendimento, localizado em Santa Cruz (INEA, 2012).

No entanto, apesar de a poluição do ar das cidades, durante muito tempo, ser atribuída basicamente às emissões industriais, com o passar dos anos o maior controle da qualidade do ar tornou obrigatório o licenciamento ambiental e, o que se observa é uma tendência à modernização das instalações industriais que têm conseguido diminuir as emissões atmosféricas. Por outro lado, o rápido crescimento da frota veicular aumentou significativamente a emissão de poluentes na atmosfera, sendo hoje a principal fonte na degradação da qualidade do ar nas regiões metropolitanas do Brasil.

A literatura médica aponta o material particulado como sendo um poluente bastante perigoso com forte influência no aumento da morbidade e da mortalidade da população, mesmo quando estão em baixas concentrações, dentro dos padrões internacionais de qualidade do ar (DAUMAS et al. 2004). Os mais atingidos são principalmente crianças e idosos, fato já verificado em países da Europa (CLANCY et al. 2002; GERVOIS et al. 1977), América do Norte (JACOBSON, 1984; LEVY et al. 1977; MAZUMDAR \& SUSSMAN, 1983; SCHIMMEL \& MURAWSKI, 1976), América do Sul (BORJA-ABURTO et al. 1997; CIFUENTES et al. 2000; OSTRO et al. 1996), inclusive no Brasil (BRAGA et al. 1999; FREITAS et al. 2004; GOUVEIA \& FLETCHER, 2000a; GOUVEIA \& FLETCHER, 2000b; GOUVEIA et al. 2006; SALDIVA et al. 1995).

As associações positivas entre morbidade e mortalidade e o material particulado, são mais evidentes nos grandes centros urbanos devido à poluição industrial, mas principalmente veicular. No entanto, trabalhos apontaram que a queima da palha da cana de açúcar (ARBEX et al. 2000), 
e a atividade de mineração (BRAGA et al. 2007) atuam de forma semelhante à poluição atmosférica produzida por combustíveis fósseis em grandes centros urbanos (CANÇADO et al. 2006).

É importante destacar que embora a qualidade do ar possa ser pior em bairros mais ricos, o que não é o habitual já que as indústrias com potencial poluidor buscam as periferias, onde o valor da terra é mais baixo, as taxas de mortalidade geral estão relacionadas às áreas periféricas (JACOBSON, 1984), onde predominam os determinantes sociais em saúde, que são os fatores sociais, econômicos, culturais, étnicos/raciais, psicológicos e comportamentais que influenciam a ocorrência de problemas de saúde e seus fatores de risco na população (Comissão Nacional sobre Determinantes Sociais da Saúde, CNDSS, 2008).
Assim, o objetivo deste trabalho é identificar as áreas que mais emitem e concentram poluentes atmosféricos, quais são as pessoas mais vulneráveis e suscetíveis aos efeitos desta poluição e onde se localizam. Conjugando-se essas informações identificaremos os espaços de risco à saúde da população.

\section{MATERIAIS E MÉTODOS}

\section{Caracterização da área de estudo}

A RMRJ (Fig. 1) concentra uma população superior a 12 milhões de pessoas, cerca de $74 \%$ de todo o Estado, sendo que 52\% desta população vivem no município do Rio de Janeiro. Estes dados indicam a existência de uma intensa polarização na região metropolitana, e principalmente no seu núcleo (Fundação Centro Estadual de Estatísticas, Pesquisa e Formação de Servidores Públicos do Rio de Janeiro, CEPERJ, 2016).

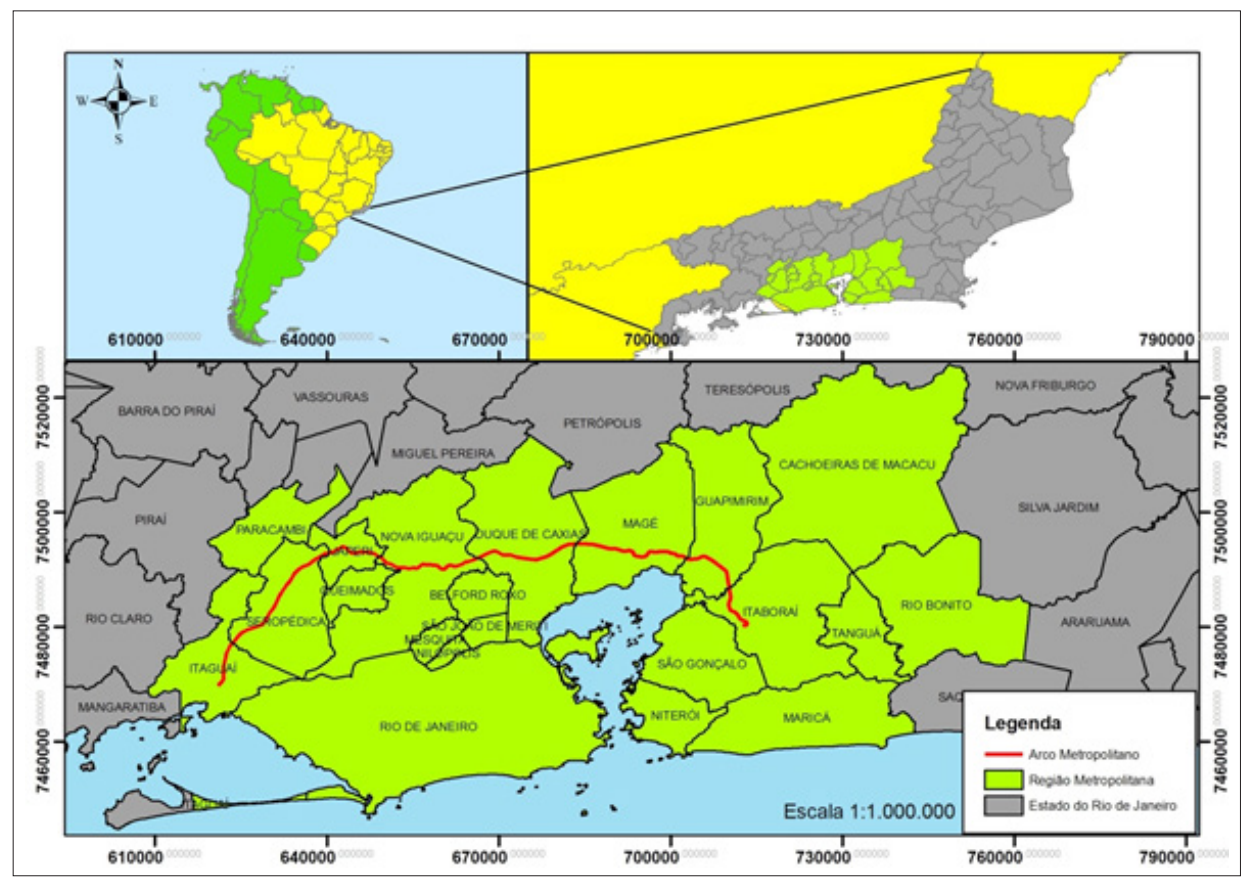

Fig. 1. Localização da RMRJ em relação ao Estado do Rio de Janeiro, Brasil e América do Sul, com destaque para o Arco Metropolitano

Fig. 1. Localización RMRJ en relación al Estado de Río de Janeiro, Brasil y América del Sur, destacando el Arco Metropolitano. 
No Brasil, as regiões metropolitanas possuem a maior concentração econômica e demográfica, justificada pela grande concentração de capital, infraestrutura e força de trabalho. Entretanto, esse espaço é marcado por grandes contradições sociais, já que muitas vezes o crescimento econômico não é acompanhado pelo atendimento das necessidades básicas da população. Isso fica materializado no espaço quando, por exemplo, existe a distribuição desigual dos serviços e equipamentos urbanos; a crescente demanda por habitações, diante da expansão das favelas ou a insegurança pública, demonstrada pelos altos índices de criminalidade.

Os municípios do Rio de Janeiro e Niterói, atual e antiga capitais do Estado do Rio de Janeiro, apresentam os melhores indicadores sociais como também as melhores condições para atrair novos investimentos de todo o Estado do Rio de Janeiro. Os municípios da Baixada Fluminense (Seropédica, Japeri, Queimados, Nova Iguaçu, Mesquita, Belford Roxo, Nilópolis, São João de Meriti e Duque de Caxias) constituemse na periferia da metrópole do Rio de Janeiro, onde vivem $27 \%$ da população da RMRJ. São municípios que apresentam concentrações industriais, mas ainda se caracterizam como cidades dormitórios com deficiências de saneamento básico, moradia, educação e saúde, e trabalho.

A grande diferença econômica entre os municípios Rio de Janeiro e Niterói e a Baixada Fluminense é fruto da fusão de dois Estados muito diferentes economicamente, Estado do Rio de Janeiro e Estado da Guanabara (antigo Distrito Federal) em 1975, o que contribuiu com o agravamento da crise que já atingia a economia do Rio de Janeiro nas décadas de 1970 e 1980, em função da perda da capital federal (SANTOS, 2003). O Arco Metropolitano (atual BR-493) foi o projeto desenvolvido na década de 1970 para superar as diferenças e promover a integração do novo Estado do Rio de Janeiro. Por isso, a concretização da obra mais de 40 anos depois de sua idealização é vista como a oportunidade de o Estado do Rio de Janeiro recuperar o seu poder de atração de investimentos, entretanto, trazendo empreendimentos com grande potencial de poluição atmosférica para áreas periféricas, como a CSA e o COMPERJ, onde a população é mais vulnerável aos efeitos da poluição do ar.

Apesar de trazerem a esperança de uma forte retomada econômica, investimentos desse porte também podem gerar altos custos ambientais para, pois a RMRJ é a segunda maior metrópole do país, e já apresenta forte concentração de carros, indústrias, e poluentes atmosféricos. Há ainda uma característica natural que agrava a qualidade do ar na RMRJ. A cidade do Rio de Janeiro se expandiu pela planície, situada ao nível do mar, e no processo de crescimento, envolveu completamente os maciços litorâneos, muitos deles ocupados.

Os maciços da Tijuca, da Pedra Branca e Gericinó-Mendanha, com altitudes em torno de 1000 metros, impõem resistência ao escoamento, reduzindo a velocidade do vento, impedindo que a brisa marítima alcance os bairros e municípios localizados no interior da RMRJ, contribuindo para a estagnação de poluentes (OLIVEIRA 2004). Na Figura 2 pode-se observar que a Serra do Mar, com altura média de 740 metros, e que em seus pontos mais altos (na cor marrom) supera os 2000 metros de altitude, contorna a planície onde está localizada a RMRJ (na cor azul).

\section{Simulação do campo de vento}

Para entender como se comportam os ventos em uma área com relevos contrastantes como a RMRJ foi feita a simulação do campo de vento na RMRJ, utilizando o modelo BRAMS. Para isso foi necessário obter os Gamrams, que são dados sobre as condições atmosféricas do modelo global, fornecidos diariamente pelo Centro de Previsão de Tempo e 


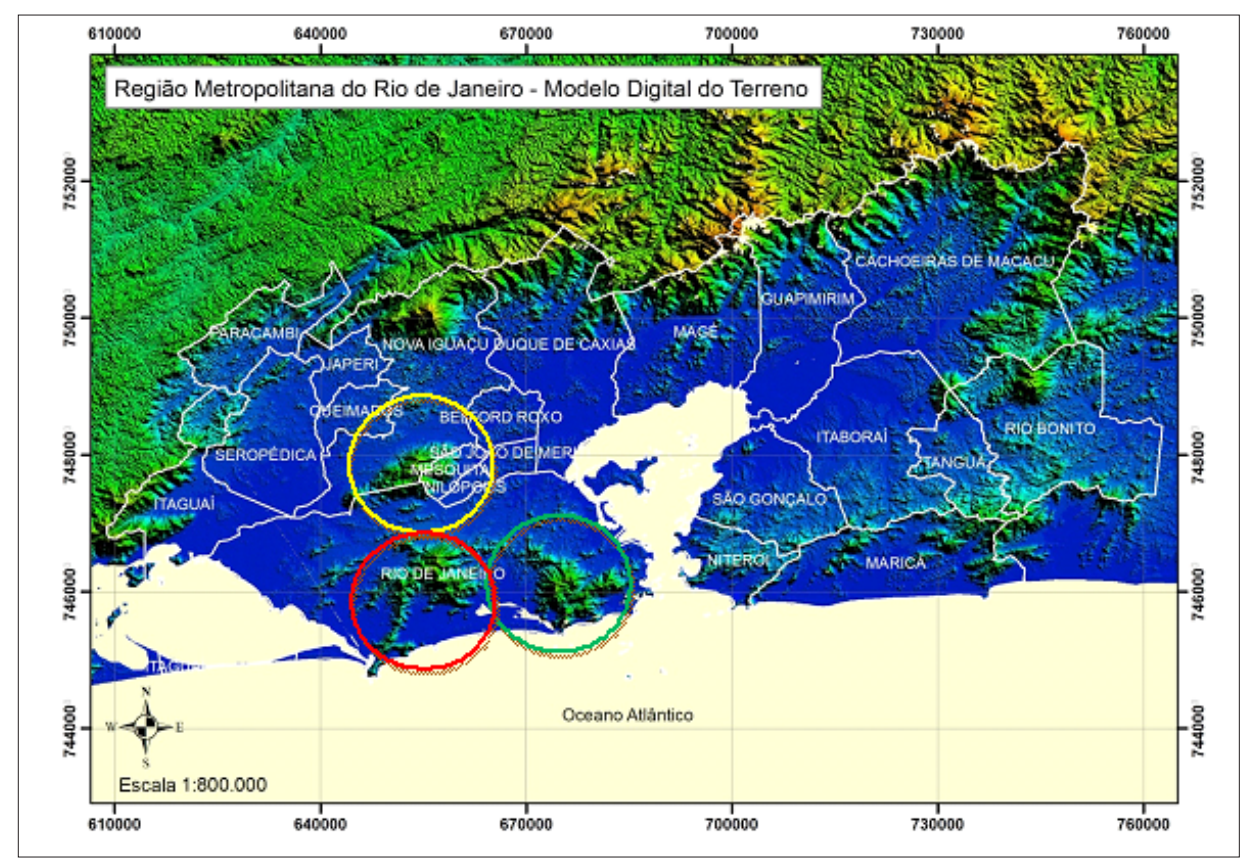

Fig. 2. A RMRJ localizada na planície (em azul) cercada pela Serra do Mar (cadeia de montanhas em verde). No município do Rio de Janeiro destacam-se os macicços da Tijuca (círculo verde), da Pedra Branca (círculo vermelho) e Gericinó-Mendanha (círculo amarelo).

Fig. 2. La RMRJ localizada en la planicie (en azul) limitada por la Serra do Mar (cadena de montañas en verde) en el municipio de Rio de Janeiro se destacan los macicos de Tijuca (círculo verde), Piedra Blanca (circulo rojo) y Gericinó-Mendanha (círculo amarillo).

Estudos Climáticos (CPTEC) do Instituto Nacional de Pesquisas Espaciais - INPE. Para acompanhar as condições do tempo nos dias e horários em que foram realizadas as simulações, utilizou-se cartas sinóticas e imagens de satélites, geradas e também fornecidas pelo CPTEC/INPE.

Para a simulação foram escolhidos 5 pontos ao longo da rodovia BR-493 e 2 pontos referentes à CSA e o COMPERJ (coordenadas 22, $9066 \mathrm{~S}$ e 43, $7404 \mathrm{~W}$ e $22,6676 \mathrm{~S}$ e $42,8470 \mathrm{~W}$, respectivamente). $\mathrm{Na}$ rodovia, os pontos escolhidos são a interseção desta com outras rodovias federais, onde espera-se um fluxo intenso de caminhões (Ponto 1: a BR101 em Itaguaí, coordenadas 22, $7667 \mathrm{~S} \mathrm{e} 42,9226 \mathrm{~W}$; Ponto 2: a BR116 em Seropédica, coordenadas 22, 6564 S e 43, $0883 \mathrm{~W}$; Ponto 3: a BR040 em Duque de Caxias, coordenadas 22, $6718 \mathrm{~S}$ e 43, 2857 W; Ponto 4: a BR465 em Magé, coordenadas 22, $7306 \mathrm{~S}$ e 43, $7158 \mathrm{~W}$; Ponto 5: a BR101 em Itaboraí, coordenadas 22, $8728 \mathrm{~S}$ e $43,8094 \mathrm{~W}$ ).

Para simular as trajetórias dos poluentes emitidos na RMRJ, a partir do campo de vento gerado pelo modelo BRAMS, optouse pelo modelo cinemático tridimensional e método não convectivo (FREITAS, 2004). Como trata-se de um modelo tridimensional representado em uma superfície, a altitude atingida por uma partícula ou poluente ao longo da trajetória de parcelas de ar é representada por uma escala de cores, variando do azul marinho para altitudes de até 100 metros, até o rosa para altitudes entre 1900 e 2000 metros.

As trajetórias foram simuladas a partir do ponto de emissão, por um período de 48 horas, em situações bastante distintas: nos 
horários de 9 e 18 horas, que apresentam grande fluxo de veículos; nas alturas de 0 metros e 70 metros, para o escapamento dos veículos (rodovia) e chaminés das indústrias, respectivamente; no meses de Janeiro e Julho, verão e inverno respectivamente, para verificar o comportamento das trajetória dos poluentes nas estações de verão e inverno quando havia o predomínio do Anticiclone Subtropical do Atlântico Sul, responsável pelo tempo bom no Rio de Janeiro.

\section{Áreas com potencial para concentrar poluentes}

Para identificar as áreas que mais liberam e concentram poluentes atmosféricos foi utilizado o software ArcGis, e através da ferramenta Wheighted Overlay foram considerados os parâmetros uso do solo, rodovias, indústrias, relevo e bacias aéreas, atribuindo pesos e percentual de influência, segundo a bibliografia consultada (CHIESA et al. 2008; GREGÓRIO, 2011; SOUZA \& SANT'ANNA NETO, 2009).

O parâmetro uso do solo foi o que recebeu maior percentual de influência por definir as áreas da cidade com maior produção de poluentes. Nas áreas com maior densidade populacional há mais veículos circulando, por isso o peso atribuído foi o máximo. Nas áreas com média e baixa densidades há menos veículos e o peso foi diminuindo proporcionalmente. As áreas que não são habitadas receberam peso mínimo, rocha, vegetação arbórea e campo.

As indústrias são responsáveis por menos poluição do ar que os veículos, respectivamente $23 \%$ e $77 \%$ (INEA, 2009), por isso têm um percentual menor de influência na produção de poluentes (20\%). As áreas próximas das indústrias estão mais expostas à poluição. Foi considerado um raio de 1 quilômetro para essas áreas, que receberam o peso máximo para a concentração dos poluentes. Já as áreas distantes além de 5 quilômetros receberam peso mínimo, pois à medida que a distância da indústria aumenta, os poluentes se dispersam. Os tipos de indústria também foram considerados, sendo o maior peso dado à atividade industrial mais poluente segundo o INEA (2009).

O parâmetro rodovias considerou as principais vias de circulação da RMRJ e, apesar de a maior parte da poluição ser produzida pelos veículos, a influência atribuída às rodovias foi equivalente àquela atribuída às indústrias (20\%). Isso porque ao considerar as vias que atravessam áreas urbanas, onde o fluxo é mais intenso, estão acumulando peso e sendo consideradas como as áreas de maior emissão dentro de uma área já avaliada como de grande emissão de poluentes, enquanto que, ao passarem em áreas não urbanas, onde o fluxo é menor, estão acumulando menos peso.

Os parâmetros relevo e bacias aéreas receberam menores percentuais de influência (15\%), pois embora sejam determinantes para a concentração de poluentes, não são emissores. No parâmetro relevo foi atribuído maior peso às planícies, considerando também as encostas com até 100 metros, que formam as bacias aéreas, onde os poluentes tendem a se concentrar. Acima de 100 metros de altitude foi atribuído peso mínimo, pois a partir deste ponto os poluentes iniciam o processo de dispersão.

\section{Perfil da população mais vulnerável à poluição}

Com as informações obtidas sobre As Causas Sociais das Iniquidades em Saúde no Brasil (CNDSS, 2008) como também a literatura médica citada foi construído um índice sintético para o reconhecimento das desigualdades de condição de vida e saúde presentes na RMRJ, chamado de Índice de Condição de Vida e Saúde (ICVS). Os indicadores criados têm o setor censitário como unidade espacial e foram baseados nos dados do Censo Demográfico de 2010. 
O marco teórico de referência foi uma adaptação da proposta desenvolvida por CASTELLANOS (1994) às características citadas na literatura médica sobre grupos populacionais mais suscetíveis aos riscos de morbidade e mortalidade.

\section{TABela 1. Dimensões e IndiCadores utilizados na CONSTRUÇão do ICVS}

\section{TABLA 1. Dimensiones E INDICADORES UTILIZADOS EN LA CONSTRUCCIÓN DEL ICVS}

\begin{tabular}{|c|c|c|}
\hline Dimensão & Indicador & Avalia \\
\hline \multirow{3}{*}{$\begin{array}{l}\text { Saneamento } \\
\text { Básico }\end{array}$} & $\begin{array}{l}\text { Percentual de domicílios abastecidos por água encanada } \\
\text { da rede geral. }\end{array}$ & \multirow{3}{*}{$\begin{array}{l}\text { O saneamento básico, } \\
\text { determinante para as condições } \\
\text { de saúde da população. }\end{array}$} \\
\hline & $\begin{array}{l}\text { Percentual de domicílios com esgotamento sanitário } \\
\text { ligado à rede geral. }\end{array}$ & \\
\hline & $\begin{array}{l}\text { Percentual de domicílios com lixo coletado por serviço } \\
\text { de limpeza. }\end{array}$ & \\
\hline \multirow{2}{*}{ Demografia } & Percentual da população com idades entre 0 e 5 anos. & \multirow{2}{*}{$\begin{array}{l}\text { Os grupos populacionais com } \\
\text { menor resistência à poluição } \\
\text { atmosférica. }\end{array}$} \\
\hline & Percentual da população com idade superior a 65 anos. & \\
\hline \multirow{2}{*}{ Renda } & Renda média dos responsáveis pelos domicílios. & \multirow{2}{*}{$\begin{array}{l}\text { O poder de consumo, de } \\
\text { alimentos a medicamentos, } \\
\text { que interfere na resistência à } \\
\text { poluição. }\end{array}$} \\
\hline & $\begin{array}{l}\text { Percentual de responsáveis com renda inferior a } 2 \\
\text { salários mínimos. }\end{array}$ & \\
\hline \multirow{2}{*}{ Educação } & $\begin{array}{l}\text { Percentual de responsáveis pelo domicílio com ensino } \\
\text { médio completo. }\end{array}$ & \multirow{2}{*}{$\begin{array}{l}\text { O grau de instrução que } \\
\text { influencia a consciência sobre } \\
\text { o risco. }\end{array}$} \\
\hline & $\begin{array}{l}\text { Percentual da população analfabeta com } 10 \text { anos de } \\
\text { idade ou mais. }\end{array}$ & \\
\hline
\end{tabular}

Os setores censitários foram divididos utilizados pela Organização das Nações em grupos, de acordo com o nível de Unidas - ONU (PNUD, 2005).

\section{Tabela 2. Critério da ONU Para Classificação adaptado para Condição de Vida.}

Tabla 2. Criterios de ONU Para Clasificación, AdAPTAdo Para Condiciones de Vida.

\begin{tabular}{|l|l|l|}
\hline IDH & Nível de Desenvolvimento & Condição de Vida \\
\hline Acima de 0,80 & Muito altow & Muito boa \\
\hline Entre 0,70 e 0,79 & Alto & Boa \\
\hline Entre 0,55 e 0,69 & Médio & Média \\
\hline Abaixo de 0,55 & Baixo & Baixa \\
\hline
\end{tabular}




\section{Mapa dos espaços de risco à saúde}

A metodologia deste trabalho consiste na produção de mapas para espacialização das informações sobre as áreas com potencial para concentrar poluentes, como também das áreas onde localiza-se a população com perfil mais vulnerável aos efeitos da poluição atmosférica. Assim, a partir do cruzamento desses dois mapas é possível conceber o mapa dos espaços de risco à saúde. Ele é o resultado da diferença entre as categorias utilizadas nos mapas anteriores, representada em cinco categorias de risco.

Assim, como está resumido na matriz de risco à saúde, na figura 3 , quando o resultado for
- -3 ou -4 significa que o cenário é muito ruim e por isso o risco é muito alto;

- -2 significa que o cenário é ruim e por isso o risco é alto;

- -1 significa que o cenário é médio e por isso o risco é médio também;

- 0 significa que o cenário é bom e por isso o risco é baixo;

- 1 a 3 significa que o cenário é muito bom e por isso o risco é muito baixo;

- 4 a 8 significa que não há dados.

\begin{tabular}{|c|c|c|c|c|c|}
\hline \multirow{2}{*}{$\begin{array}{l}\text { Condição de } \\
\text { Vida }\end{array}$} & \multicolumn{5}{|c|}{ Potencial para concentrar poluentes } \\
\hline & $\begin{array}{l}\text { Muito baixo } \\
1\end{array}$ & $\begin{array}{l}\text { Baixo } \\
2\end{array}$ & $\begin{array}{l}\text { Médio } \\
3\end{array}$ & $\begin{array}{l}\text { Alto } \\
4\end{array}$ & $\begin{array}{l}\text { Muito alto } \\
5\end{array}$ \\
\hline Baixa 1 & 0 & -1 & -2 & -3 & -4 \\
\hline Média 2 & 1 & 0 & -1 & -2 & -3 \\
\hline Boa 3 & 2 & 1 & 0 & -1 & -2 \\
\hline Muito boa 4 & 3 & 2 & 1 & 0 & -1 \\
\hline Sem dados 9 & 8 & 7 & 6 & 5 & 4 \\
\hline
\end{tabular}

Fig. 3. Matriz de risco à saúde: relação entre a condição de vida e o potencial da área para emitir/concentrar poluentes.

Fig. 3. Matriz de riesgo a la salud: relación entre la condición de vida y el potencial de área para emitir/concentrar contaminantes.

\section{RESULTADOS}

\section{Simulação do campo de vento - Verão}

No dia 12 de Janeiro o Estado do Rio de Janeiro estava parcialmente encoberto e a frente fria intensa estava posicionada sobre a Argentina, Uruguai e sul do Brasil (Figs. 4 e 5).

$\mathrm{Na}$ imagem do escoamento tipo brisa (Fig. 6), no horário da manhã, devido ao maior aquecimento do topo da Serra do Mar, observa-se o escoamento de ventos subindo 

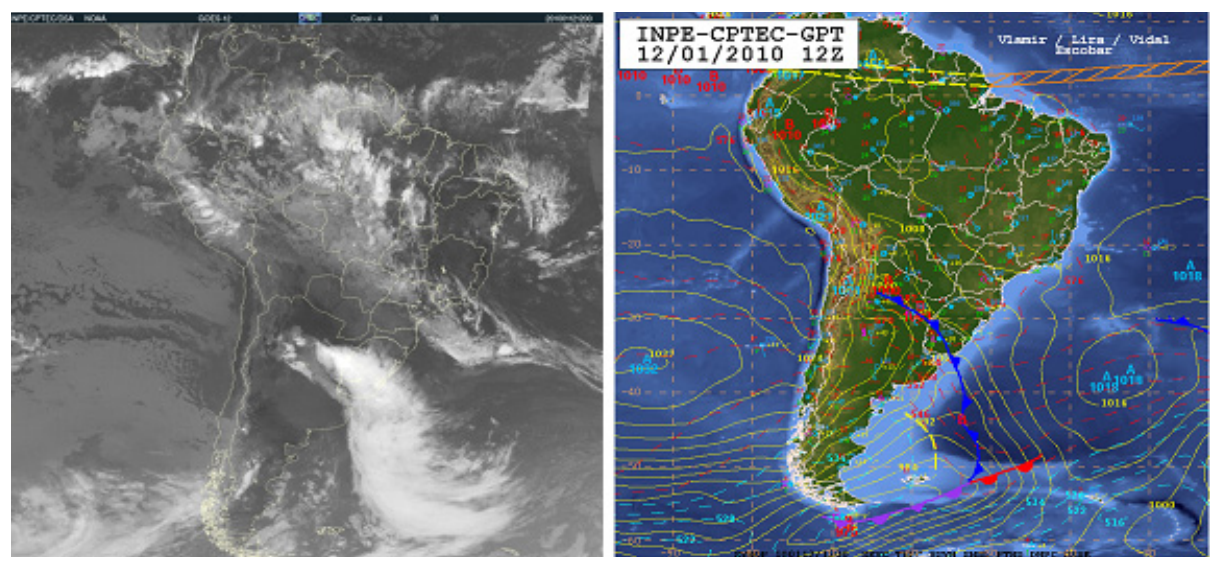

Fig. 4 e 5. Imagem de satélite e carta de superfície do dia 12 de Janeiro de 2010, 12 UTC

Fig. 4 y 5. Imagen de satélite y carta de superfície del día 12 de Enero de 2010, 12 UTC

a encosta em direção ao cume, em ambas as vertentes (brisa de vale). Na planície litorânea observa-se o efeito da brisa marítima na porção leste da RMRJ, enquanto na oeste os ventos vindos do mar têm a velocidade reduzida em função do relevo, ficando muito mais fracos. É notória a influência dos três maciços no campo de vento.

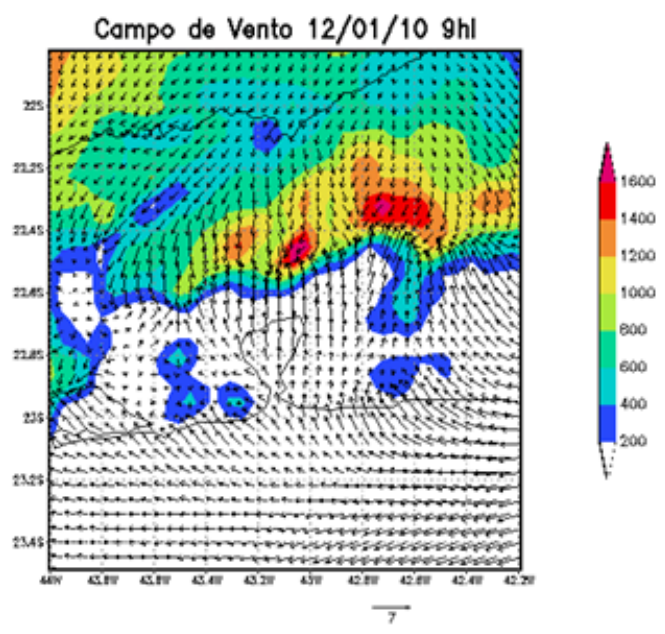

Fig. 6. Escoamento do tipo brisa - 12/01/2010, 9 horas local.

Fig. 6. Escurrimiento del tipo brisa - 12/01/2010, 9:00 horas local.

Na manhã do dia 12 de Janeiro (Figs. 7 e 8) as trajetórias emitidas dos pontos 3, 4, 5 e COMPERJ, sob a influência da brisa marítima, deslocam-se para norte em baixa altitude durante o início do percurso devido à presença do relevo, fazendo com que os poluentes circulem próximos ao solo contaminando o ar próximo à superfície por mais tempo. Ao ascender para ultrapassar a Serra do Mar, as trajetórias passam a 
receber influência da circulação de grande escala e se elevam até 2000 metros do solo. Nos pontos 1, 2 e CSA onde os ventos estavam mais fracos devido a presença do Maciço da Pedra Branca, as trajetórias emitidas se elevaram menos e chegaram no máximo a 1500 metros. A trajetória do ponto 1 vai para oeste em baixa altitude, em decorrência dos ventos fracos e variáveis proporcionados pela barreira formada pelo maciço da Pedra Branca.

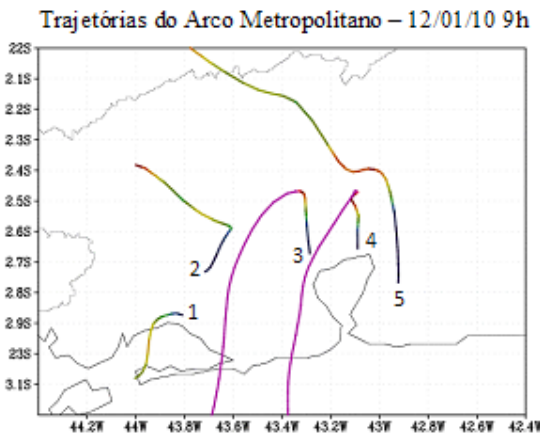

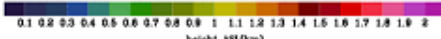

Trajetórias CSA e COMPERJ - 12/01/10 9h

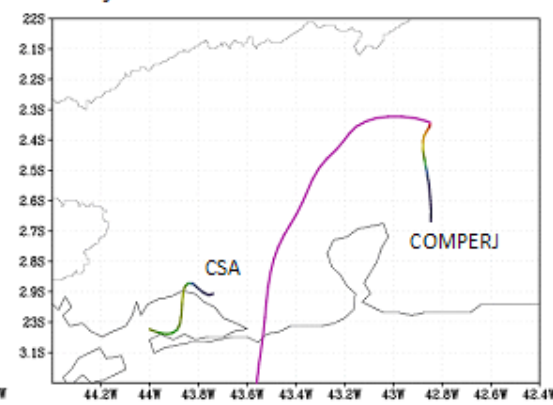

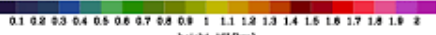

Figs. 7 e 8. Trajetórias simuladas para o dia 12/01/2010, 9 horas local.

Figs. 7 y 8. Trayectorias simuladas para el día 12/01/2010, 9:00 horas local.

$\mathrm{Na}$ imagem do escoamento do dia 12 de Janeiro, 18 horas (Fig. 9), percebe-se uma mudança na circulação atmosférica. A brisa marítima continua atuando, no entanto, diferentemente do horário da manhã, influencia mais as porções central e oeste da RMRJ com um fluxo bastante intenso, enquanto que na porção leste percebe-se ventos fracos de nordeste, na área mais protegida pelo relevo.

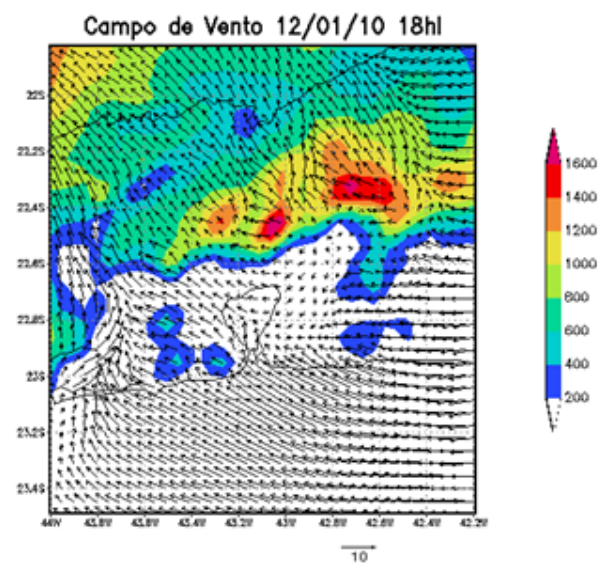

Fig. 9. Escoamento do tipo brisa - 12/01/2010, 18 horas local

Fig. 9. Escurrimiento tipo brisa - 12/01/2010, 18:00 horas local 
No fim da tarde do dia 12 de Janeiro (Figs. 10 e 11) as trajetórias deslocam-se em baixa altitude durante grande parte do percurso, alcançando o máximo de 800 metros do solo, avançando mais sobre o interior do continente do que no horário da manhã, levando poluentes para localidades distantes das fontes de emissão. Isto pode gerar sérios problemas à população porque as trajetórias se elevaram menos e percorreram grandes distâncias bem próximas à superfície.
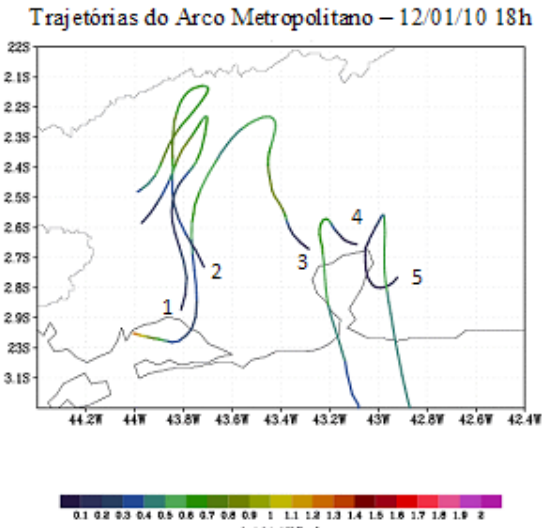

(⿻)
Trajetórias CSA e COMPERJ - 12/01/10 18h

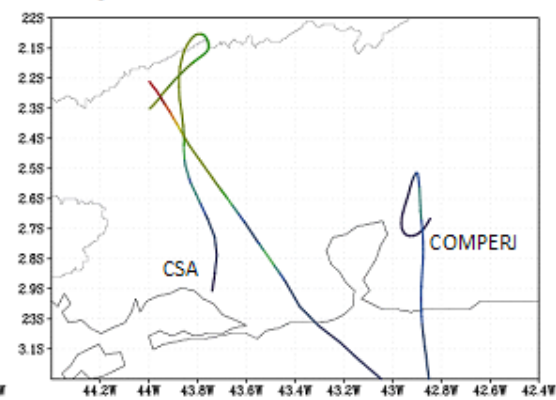

(t)

Figs. 10 e 11. Trajetórias simuladas para o dia 12/01/2010, 18 horas local

Figs. 10 y 11. Trayectorias simuladas para el día 12/01/2010, 18:00 horas local

\section{Simulação do campo de vento - Inverno}

No dia 11 de Julho a fraca nebulosidade sobre o Estado do Rio de Janeiro mantinha o tempo estável e com temperatura amena para o inverno. O cavado no litoral do Rio de Janeiro mantinha o tempo nublado. O sistema frontal intenso estava posicionado sobre a Argentina e Uruguai (Figs. 12 e 13).
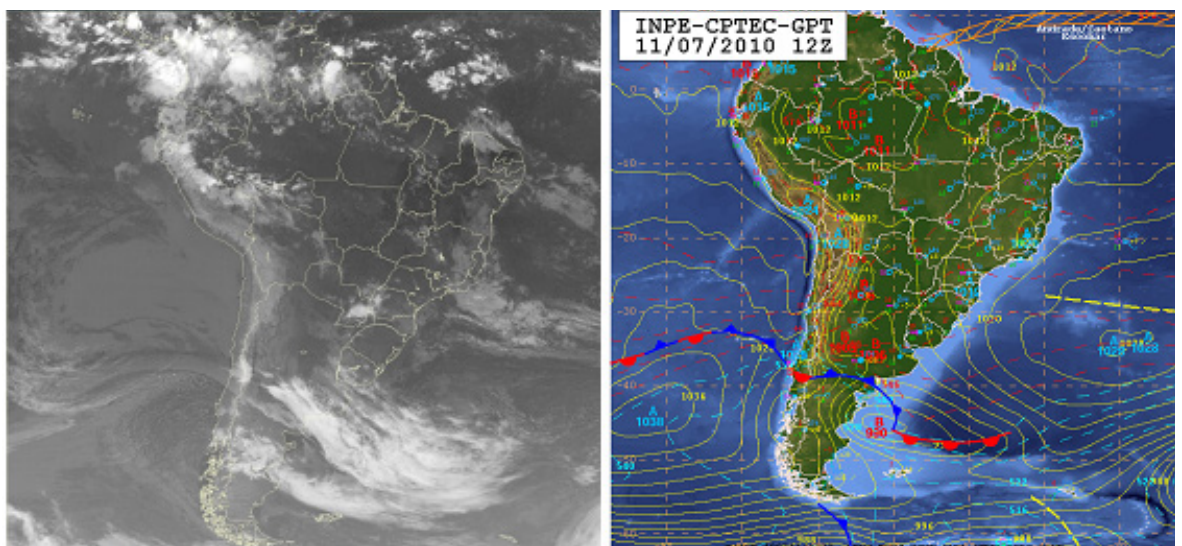

Figs. 12 e 13. Imagem de satélite e carta de superfície do dia 11 de julho de 2010, 12 UTC.

Figs. 12 y 13. Imagen de satélite y carta de superficie del día 11 de julio de 2010, 12 UTC. 
Na manhã do dia 11 de julho (Fig. 14) observa-se o escoamento dos ventos paralelos à costa do Rio de Janeiro que têm sua velocidade reduzida pelo relevo, ficando a Bacia Aérea I isolada da sua atuação.

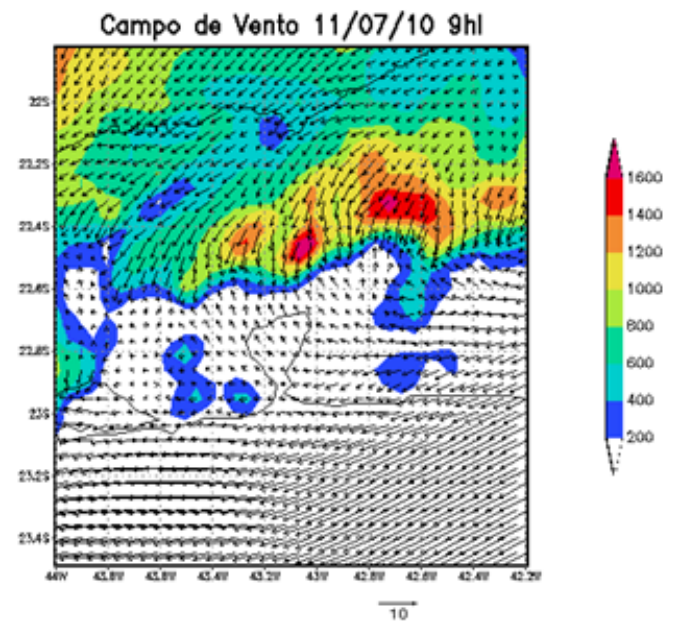

Fig. 14. Escoamento do tipo brisa. 11/07/2010, 9 horas local.

Fig. 14. Escurrimiento del tipo brisa. 11/07/2010, 9:00 horas local.

Na manhã do dia 11 de Julho (Figs. 15 e 16) as trajetórias têm comportamento semelhante ao observado na manhã de verão do dia 12 de janeiro. As trajetórias emitidas dos pontos 3, 4, 5 e COMPERJ se deslocam para norte em baixa altitude e ao ascenderem para ultrapassar a Serra do Mar, se elevam rapidamente direcionandose para o oceano, influenciadas pela circulação de grande escala. No inverno, as trajetórias emitidas a partir da rodovia se elevaram menos do que no verão, embora tenham alcançado 1500 metros da superfície.

A trajetória emitida do COMPERJ, mesmo no inverno, conseguiu se elevar a 2000 metros.
As trajetórias emitidas na Bacia Aérea I (pontos 1 e 2 do Arco Metropolitano e a CSA) se elevaram a 700 metros da superfície, menos que as trajetórias das demais bacias aéreas como também menos do que na simulação do verão, quando alcançou 1100 metros. Nesta área os poluentes demoram mais para serem dispersados, principalmente no inverno, quando ficam mais tempo próximo à superfície, afetando a saúde da população. 

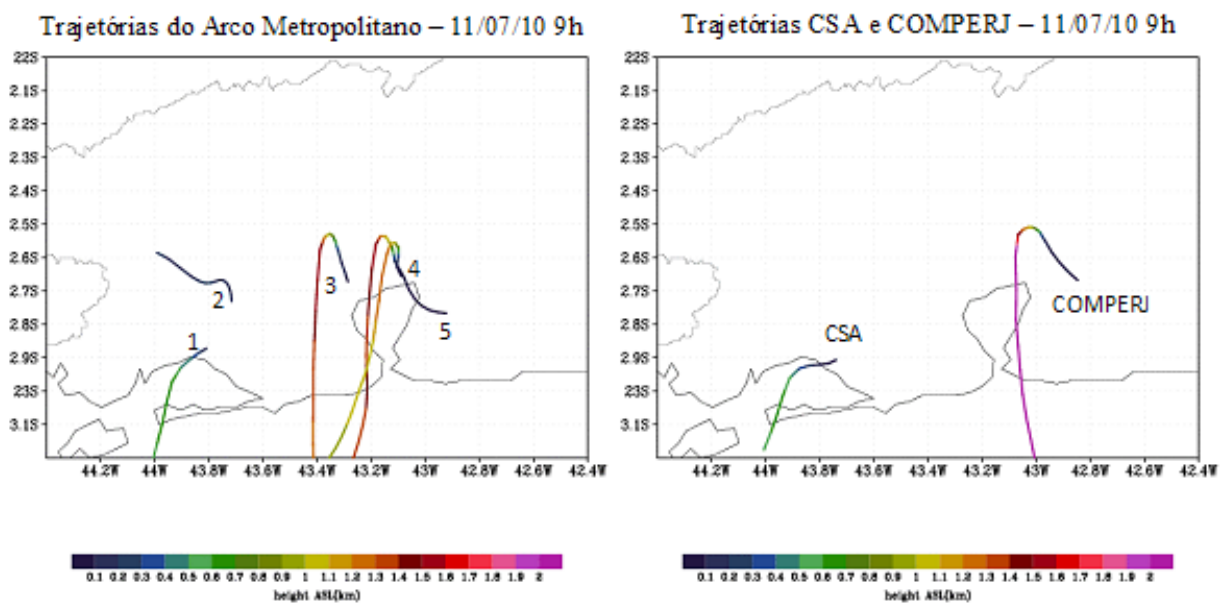

Figs. 15 e 16. Trajetórias simuladas para o dia 11/07/2010, 9 horas local.

Figs. 15 y 16. Trayectorias simuladas para el día 11/07/2010, 9:00 horas local.

No fim da tarde do dia 11 de Julho (Fig. 17) observa-se o escoamento dos ventos paralelos à costa do Rio de Janeiro com deslocamento para o interior do continente com mais intensidade do que no período da manhã, mas ainda assim têm sua velocidade reduzida pelo relevo, ficando a Bacia Aérea I isolada da sua atuação.

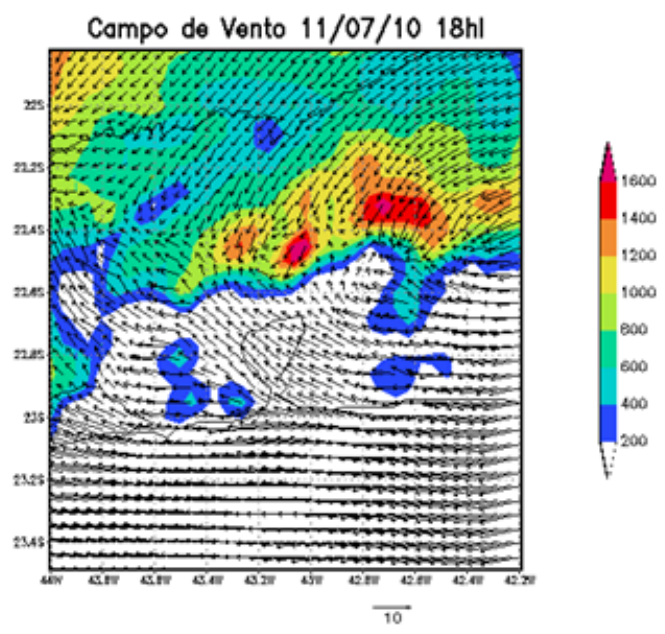

Fig. 17. Escoamento do tipo brisa - 11/07/2010, 18 horas local

Fig. 17. Escurrimiento tipo brisa - 11/07/2010, 18:00 horas local 
No fim da tarde do dia 11 de Julho as trajetórias têm o deslocamento semelhante ao observado pela manhã, no entanto se elevam bem menos. As trajetórias emitidas dos pontos 3, 4, 5 e COMPERJ se deslocam em baixa altitude no início do percurso e, ao transporem a Serra do Mar, são influenciadas pela circulação de grande escala e se dirigem para o oceano, passando a menos de 400 metros da superfície por sobre as áreas central e oeste da RMRJ. Já as trajetórias emitidas dos pontos 1,2 e CSA não se elevam como as demais, deslocandose para o interior do continente a menos de 300 metros da superfície. Neste horário, os poluentes emitidos na Bacia Aérea I não se dispersaram, ficando concentrados na própria bacia aérea (Figs. 18 e 19).
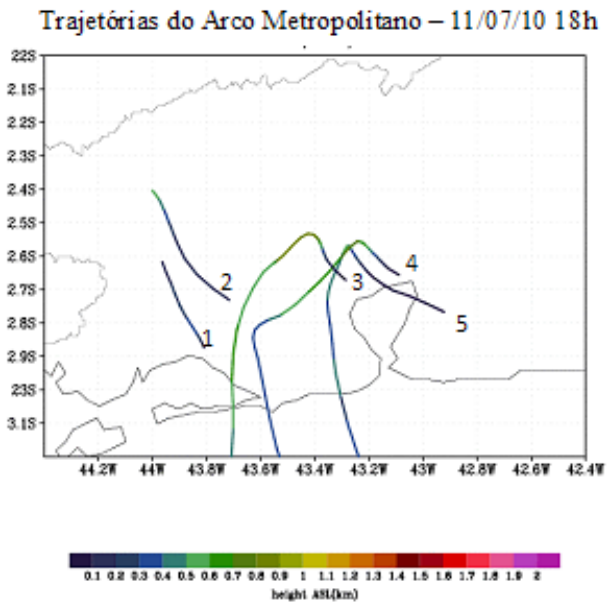

Trajetórias CSA e COMPE RJ - 11/07/10 18h

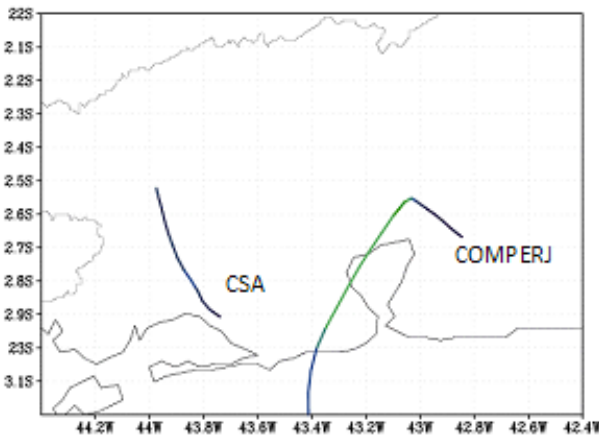

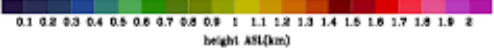

Fig. 18 e 19. Trajetórias simuladas para o dia 11/07/2010, 18 horas local

Fig. 18 y 19. Trayectorias simuladas para el dia 11/07/2010, 18:00 horas local

\section{Áreas com potencial para concentrar poluentes}

O mapeamento do potencial para concentração de poluentes (Fig. 20) mostra que as áreas com potencial muito alto são as principais vias de circulação que atravessam áreas com alta densidade populacional, em áreas de planície situadas em bacias aéreas com dificuldades para dispersão dos poluentes. Essas áreas foram identificadas ao longo das rodovias BR101, BR116, BR040 e BR465, no município do Rio de Janeiro e na Baixada Fluminense. Há também algumas áreas pontuais ao longo de vias em Niterói, São Gonçalo, Guapimirim e Magé. 


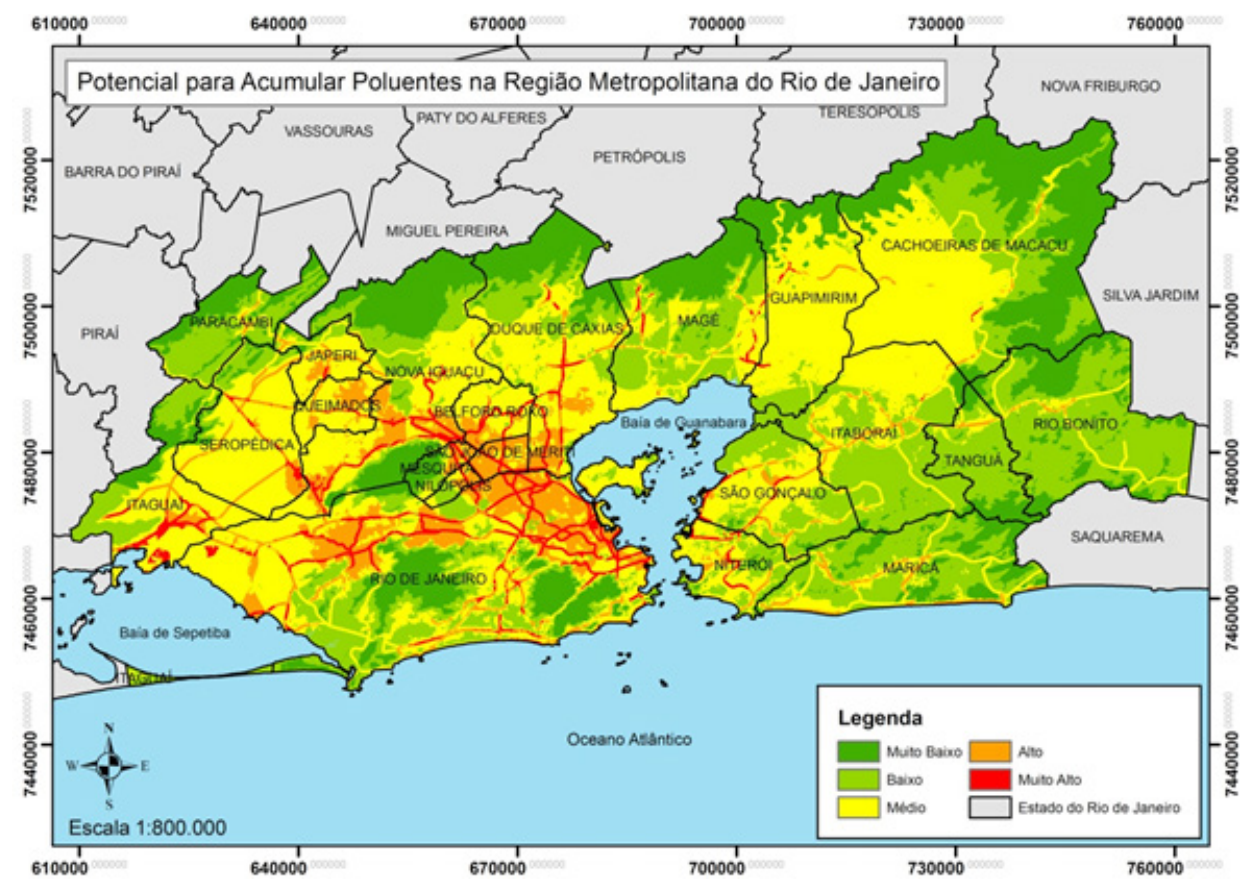

Fig. 20. Áreas com potencial para acumular poluentes atmosféricos RMRJ.

Fig. 20. Áreas con potencial para acumular contaminantes atmosféricos en RMRJ.

As áreas com alto potencial para concentrar poluentes coincidem com áreas de alta densidade populacional, como Zona Norte do Rio de Janeiro; média densidade populacional com influência de atividade industrial, como os municípios São João de Meriti, Belford Roxo, Nilópolis, Mesquita e Nova Iguaçu, na Baixada Fluminense; e baixa densidade populacional com influência de rodovias de grande circulação como áreas em Niterói, São Gonçalo, Guapimirim, Magé, Seropédica e Itaguaí. Essas áreas também localizam-se em planícies situadas em bacias aéreas com dificuldades para dispersão dos poluentes.

Com médio potencial para concentrar poluentes estão as planícies no fundo das bacias aéreas que, no entanto, não apresentam atividade industrial ou vias de circulação. A exceção é a Zona Sul do Rio de Janeiro que tem grande densidade populacional e vias com grande circulação, mas encontra-se numa estreita planície muito próxima ao mar, o que garante forte influência da brisa marítima, aliviando os efeitos da poluição atmosférica.

O potencial baixo para concentrar poluentes se refere às áreas onde apesar de o relevo ser de planície, o uso do solo está livre da urbanização e da interferência das vias de circulação. Já o potencial muito baixo para concentrar poluentes está restrito às áreas elevadas do relevo onde os poluentes conseguem se dispersar com maior facilidade, não encontrando condições para concentrar-se.

\section{Perfil da população mais vulnerável à poluição}

O mapeamento da condição de vida (Fig. 21) mostra que a população com condição de vida muito boa localiza-se principalmente nos municípios de Niterói e Rio de Janeiro. 
Na capital está para além dos bairros da Zona Sul e Barra da Tijuca, tradicionalmente com população de maior poder aquisitivo. Há também áreas no Centro, Zona Norte, Ilha do Governador, além de pontualmente em alguns municípios da Baixada Fluminense como Nova Iguaçu, Nilópolis e São João de Meriti. Este grupo caracteriza-se por ter menor percentual de crianças e idosos na população, altos níveis de renda e educação, moradia com infraestrutura de saneamento básico.

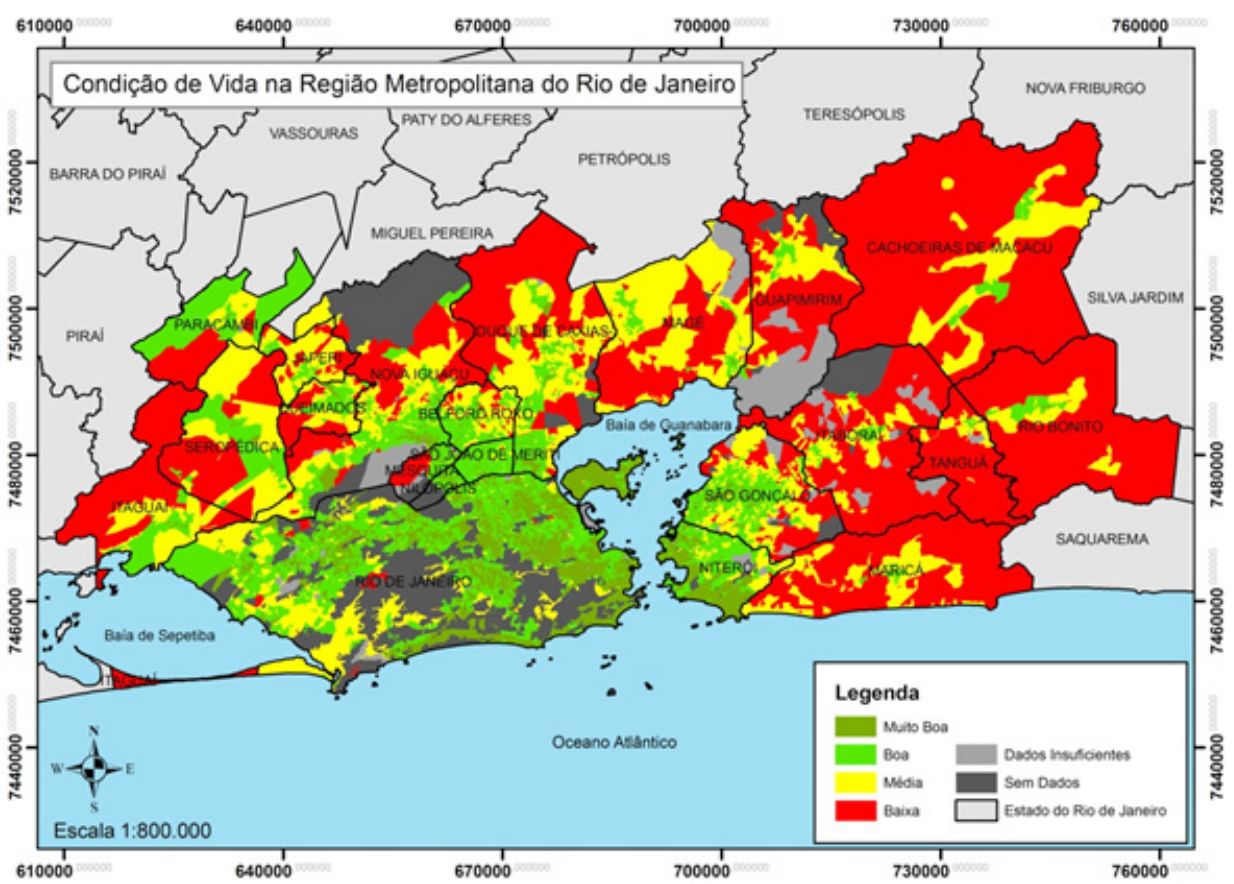

Fig. 21. A espacialização do Índice de Condição de Vida e Saúde na RMRJ.

Fig. 21. Especialización del Î́ndice de Condición de Vida y Salud en la RMRJ.

A população com boa condição de vida está presente em todos os municípios. $\mathrm{Na}$ periferia, localiza-se nas áreas centrais dos municípios, mas também ao longo das rodovias BR101, BR116, BR040 e BR465 que atravessam Seropédica, Paracambi, Japeri, Queimados, Nova Iguaçu, Belford Roxo, Nilópolis, São João de Meriti, Duque de Caxias, Magé, Guapimirim, São Gonçalo, Itaboraí, Tanguá, Mesquita, Itaguaí e Maricá. Este grupo caracteriza-se por ter um percentual mais alto de crianças e idosos na população, bons níveis de renda, instrução, moradia com infraestrutura de saneamento básico.
A população com condição de vida média localiza-se próximo às áreas centrais dos municípios da periferia, como também na extrema Zona Oeste do município do Rio de Janeiro. Este grupo caracteriza-se por ter um percentual ainda mais alto de crianças e idosos na população, médios níveis de renda, instrução ou a moradia apresenta déficit de infraestrutura de saneamento básico. Já a população com baixa condição de vida, em sua grande maioria, localiza-se no interior dos municípios periféricos, ou seja, na periferia da periferia. Este grupo caracteriza-se por ter maior percentual de crianças e idosos na população, baixos 
níveis de renda, instrução e moradia com déficit de infraestrutura de saneamento básico.

A categoria Dados Insuficientes refere-se a setores censitários com ausência de dados em pelo menos um dos indicadores. Em alguns casos o IBGE omite as informações referentes à renda da família, principalmente quando o setor tem poucos moradores, para que haja sigilo e os ganhos não sejam de fácil dedução. Já a categoria Sem Dados representa as áreas onde não há população residente por ser um maciço rochoso, uma lagoa, área industrial. Essa foi uma opção do IBGE para representação do Censo 2010.

\section{Mapa dos espaços de risco à saúde}

Os espaços de risco muito alto à saúde correspondem a um cenário muito ruim, estando representados pela cor vermelha. São áreas onde coincidem o potencial muito alto de concentração de poluentes e populações com baixa e média condição de vida e saúde; ou potencial alto de concentração de poluentes e população com baixa condição de vida e saúde. Estão localizadas em pequenas extensões ao longo de rodovias próximas a áreas industriais importantes como COMPERJ (Cachoeiras de Macacu e Itaboraí), REDUC (Duque de Caxias), Bayern (Belford Roxo), Termelétrica (Queimados e Seropédica) e CSA (Itaguaí, Seropédica e Rio de Janeiro).

Os espaços de risco alto à saúde correspondem a um cenário ruim e estão representados pela cor laranja. São áreas onde coincidem o potencial médio de concentração de poluentes e população com baixa condição de vida e saúde; ou o potencial alto de concentração de poluentes e população com média condição de vida e saúde; ou ainda o potencial muito alto de concentração de poluentes e população com boa condição de vida e saúde. Estão muito próximas dos espaços de risco muito alto à saúde, no entanto possuem maiores extensões e em sua grande maioria localizadas nos municípios da periferia, no fundo das bacias aéreas. (Fig. 22)

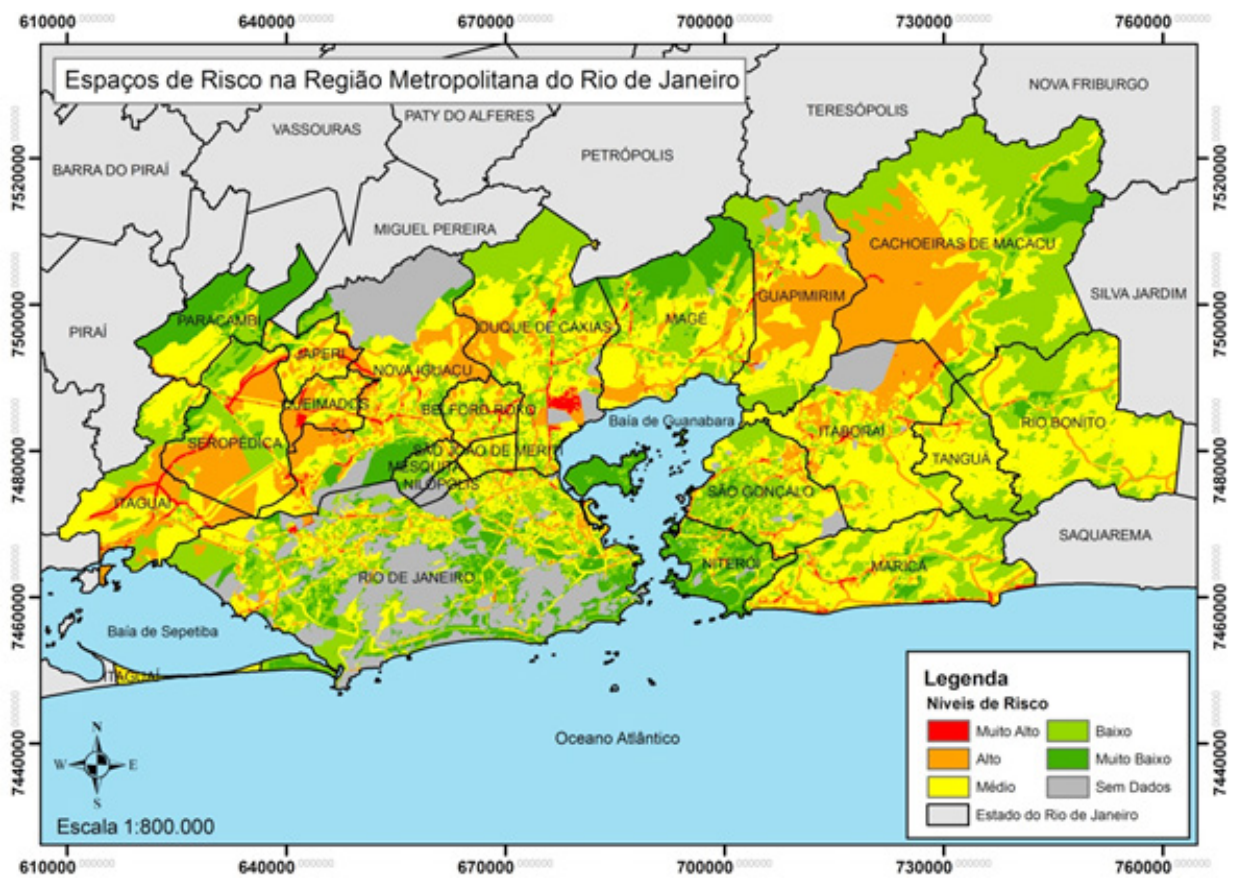

Fig. 22. Espaços de risco à saúde na Região Metropolitana do Rio de Janeiro.

Fig. 22. Espacios de riesgo a la salud en la Región Metropolitana de Rio de Janeiro. 
Os espaços de risco médio à saúde correspondem a um cenário razoável e estão representados pela cor amarela. São áreas onde coincidem o potencial baixo de concentração de poluentes e população com baixa condição de vida e saúde; ou o potencial médio de concentração de poluentes e população com média condição de vida e saúde; ou o potencial alto de concentração de poluentes e população com boa condição de vida e saúde; ou ainda o potencial muito alto de concentração de poluentes e população com muito boa condição de vida e saúde. Estão presentes em todos os municípios, mas em sua grande maioria na porção leste da RMRJ, onde há menos empreendimentos e menor população (Maricá, Tanguá e Rio Bonito).

Os espaços de risco baixo à saúde correspondem a um cenário bom e estão representados pela cor verde claro. São áreas onde coincidem o potencial muito baixo de concentração de poluentes e população com baixa condição de vida e saúde; ou o potencial baixo de concentração de poluentes e população com média condição de vida e saúde; ou o potencial médio de concentração de poluentes e população com boa condição de vida e saúde; ou ainda o potencial alto de concentração de poluentes e população com muito boa condição de vida e saúde. Estão presentes nos municípios de Niterói, São Gonçalo e Rio de Janeiro pela proximidade do mar e melhor condição de vida da população, mas também nos demais municípios onde o potencial de concentração de poluentes é muito inferior devido à presença do relevo da Serra do Mar.

Os espaços de risco muito baixo à saúde correspondem a um cenário muito bom $\mathrm{e}$ estão representados pela cor verde escuro. São áreas onde coincidem o potencial muito baixo de concentração de poluentes e população com média, boa e muito boa condição de vida e saúde; ou o potencial baixo de concentração de poluentes e população com boa e muito boa condição de vida e saúde; ou ainda o potencial médio de concentração de poluentes e população com muito boa condição de vida e saúde. Estão próximas às áreas onde foram descritas o baixo risco à saúde, no entanto ainda mais restritas nos municípios de Niterói e Rio de Janeiro, mas também em Paracambie e Magé, além de pontualmente em Rio Bonito e Cachoeiras de Macacu.

As áreas sem dados sobre risco à saúde são aquelas onde havia ausência de dados em pelo menos um dos indicadores ou ausência de população residente no mapeamento de condição de vida e saúde.

\section{DISCUSSÃO}

No verão o forte aquecimento da superfície gera turbulência térmica favorece $\mathrm{o}$ aumento da espessura da camada de mistura e a dispersão dos poluentes. Assim, podese perceber que na simulação do campo de vento para o início da manhã do dia 12 de Janeiro, as trajetórias se elevaram mais rapidamente, possibilitando a ascensão dos poluentes a níveis mais elevados da atmosfera, sendo dispersados com mais facilidade. Já na simulação do campo de vento para o fim da tarde do mesmo dia, as trajetórias ascenderam menos, em consequência do menor aquecimento da atmosfera, favorecendo a concentração de poluentes próximos à superfície, trazendo riscos à saúde da população.

No inverno as trajetórias avançam menos para o interior do continente, deslocamse em baixa altitude e, muitas vezes, são direcionadas para o mar. Isso pode ser explicado pela maior intensidade do ASAS e por sua posição em relação ao continente nesta estação do ano, prevalecendo os ventos de nordeste.

Comparando os experimentos realizados nas duas estações percebe-se que no inverno as trajetórias se elevaram menos, ficando muito mais próximas da superfície devido à atuação mais intensa do ASAS sobre o continente nesta estação do ano, 
o que provoca forte subsidência do ar. Assim, no inverno, como as trajetórias ganham menos altura e dirigem-se para o mar, a população que está ao sul dos empreendimentos, ou mais próxima do mar, é aquela que está sob maior risco. No verão, como as trajetórias ganham mais altitude e se dirigem para o interior, em maior risco está a população que localizada ao norte dos empreendimentos, ou seja, mais para o interior, muitas vezes além da Serra do Mar, como é o caso da população dos municípios serranos.

Entender os mecanismos de dispersão dos ventos contribuiu para a identificação das áreas com maior potencial para concentrar poluentes. A porção central da RMRJ, mais densa, tem mais áreas com potenciais alto e muito alto para gerar e concentrar poluentes. A porção oeste, menos densa, também apresenta áreas extensas com alto e muito alto potenciais para gerar e concentrar poluentes, mas com um agravante, tem grande dificuldade para dispersar os poluentes, como mostrou a simulação do campo de vento.

Essas informações conjugadas com a qualidade de vida da população permitiu identificar que existem, pontualmente, espaços de alto e muito alto risco à saúde em todos os municípios da RMRJ, localizados ao longo das vias de grande fluxo de veículos e próximos às áreas industriais, onde a população tem condições de vida e saúde vulneráveis. As áreas mais extensas e que apresentam alto e muito alto riscos à saúde se localizam em municípios como Itaboraí, Cachoeiras de Macacu, Guapimirim, Magé, Duque de Caxias, Nova Iguaçu, Queimados, Japeri, Seropédica e Itaguaí. São exatamente os municípios atravessados pelo Arco Metropolitano que vêm atraindo novos empreendimentos. A exceção é o município de Cachoeiras de Macacu que, no entanto, está sob influência do COMPERJ.

\section{CONCLUSÕES}

A simulação do campo de vento possibilitou observar que a orientação das vertentes e a altitude do relevo da RMRJ influenciam na direção dos ventos de superfície, interferindo no transporte atmosférico, dificultando a dispersão de poluentes em algumas áreas da metrópole, fortalecendo a existência do que chamamos de bacias aéreas.

A CSA está localizada no extremo oeste da RMRJ, área que apresentou maior dificuldade para dispersar os poluentes que, no entanto, já existem muitas indústrias e está desenvolvendo um potencial para atrair outras mais. Apesar da densidade populacional ser baixa no entorno da CSA, há um grande percentual de população vulnerável nas áreas próximas, existindo um risco maior de a população desenvolver problemas respiratórios relacionados à má qualidade do ar.

O COMPERJ está localizado no extremo leste da RMRJ, área que apresentou maior facilidade para dispersar poluentes em relação às demais, além disso, o empreendimento está em uma área vegetada afastada das áreas urbanas, que também são de baixa densidade populacional, apesar da proporção de população vulnerável ser grande. Assim, pode-se dizer que a localização do COMPERJ é menos problemática do que a localização da CSA. No entanto, por estar em uma área com poucos empreendimentos e com emissão de poluentes bastante inferior às demais, o funcionamento pleno do COMPERJ influenciará a qualidade do ar local.

Assim, conclui-se que os empreendimentos trazidos para alavancar a retomada econômica do Rio de Janeiro estão localizados em espaços de risco alto (COMPERJ) e muito alto (CSA e Arco Metropolitano) para a saúde da população, não apenas pelo próprio potencial poluidor das indústrias, mas também por estarem 
localizados em áreas com médio, alto e muito alto potenciais para concentrarem poluentes que tornam os risco ainda maiores por terem população com condição de vida e saúde vulneráveis. É preciso desenvolver estudos mais criteriosos para a emissão de licenças de instalação e operação para determinados tipos de empreendimentos a fim de preservar a qualidade de vida da população.

\section{REFERÊNCIAS}

ARBEX, M.A., BOHM, G. M., SALDIVA, P. H. N., CONCEIÇÃO, G. M., POPE, A. C., \& BRAGA, A. L. (2000). Assessment of the effects of sugar cane plantation burning on daily counts of inhalation therapy. J Air Waste Manag Assoc, 50(10), 1745-9.

BORJA-ABURTO, V. H., LOOMIS, D. P., BANGDIWALA, S. L., SHY, C. M., \& RASCON-PACHECO, R. A. (1997). Ozone suspended particulates, and daily mortality in Mexico City. American Journal of Epidemiology, 145, 258-68.

BRAGA, A. L., CONCEIÇÃO, G. M., PEREIRA L. A., KISHI, H. S., PEREIRA J. C., \& ANDRADE, M. F. (1999). Air pollution and pediatric respiratory hospital admissions in São Paulo, Brazil. Journal Environmental Medicine, 1, 95-102.

BRAGA, A. L. F., PEREIRA L. A. A., PROCÓPIO, M., ANDRÉ, P. A., \& SALDIVA, P. H. N. (2007) Associação entre poluição atmosférica e doenças respiratórias e cardiovasculares na cidade de Itabira, Minas Gerais, Brasil. Cad. Saúde Pública, 23 (4), S570-S578.

CANÇADO, J. E. D., BRAGA, A., PEREIRA, L. A. A., ARBEX, M. A., SALDIVA, P. H. N., \& SANTOS, U. P. (2006). Repercussões clínicas da exposição à poluição atmosférica. J Bras Pneumol, 32 (2), S23-S29.
CASTEllanOS, P. L. (1994). Proyecto: sistemas nacionales de vigilancia de la situación de salud según condiciones de vida y del impacto de las acciones de salud y bienestar. Washington: Organización Panamericana de la Salud.

CHIESA, A., WESTPHAL, M., \& AKERMAN, M. (2008). Doenças respiratórias agudas: um estudo das desigualdades em saúde. Cad. Saúde Pública, 24(1), 55-69.

CEPERJ - Fundação Centro Estadual de Estatísticas, Pesquisa e Formação de Servidores Públicos do Rio de Janeiro (2016). Recuperado de: http://www.ceperj. rj.gov.br/ceep/info_territorios/divis regional.html.

CIFUENTES, L. A. VEJA, J. KOPFER, K., \& LAVE, L. B. (2000). Effect of the fine fraction of particulate matter versus the coarse mass and other pollutants on daily mortality in Santiago, Chile. J Air Waste Manag Assoc, 50, 1287-98.

CLANCY L., GOODMAN P., SINCLAIR H., \& DOCKERY D. W. (2002). Effect of air-pollution control on death rates in Dublin, Ireland: an intervention study. Lancet, 360 (9341), 1210-4.

CNDSS - Comissão Nacional sobre Determinantes Sociais da Saúde (2008). As Causas Sociais das Iniqüidades em Saúde no Brasil. Rio de Janeiro: Editora Fiocruz.

DAUMAS, R. P., MENDONÇA, G. A. S., \& LEON, A. P. (2004). Poluição do ar e mortalidade em idosos no município do Rio de Janeiro: análise de série temporal. Cad. Saúde Pública, 20, 311-319.

FREITAS, C., BREMNER, S. A., GOUVEIA, N., PEREIRA, L. A. A., \& SALDIVA, P. H. N. (2004). Internações 
e óbitos e sua relação com a poluição atmosférica em São Paulo, 1993 a 1997. Revista de Saúde Pública, São Paulo, 38(6), 751-7.

GERVOIS, M., DUBOIS, G., GERVOIS, S., QUÉ-TÚ, J-M., MULLER A., \& VOISIN, C. (1977). Pollution atmosphérique deniveau modéré et affections respiratoires d'origine banale. Enquête de Demain - Quiévrechain (Nord.). Revue d'Epidemiologie et de Santé Publique, 25, 195-207.

GOUVEIA, N. \& FLETCHER, T. (2000a). Time series analysis of air pollution and mortality: effects by cause, age and socioeconomic status. J Epidemiol Community Health, 54, 750-5.

GOUVEIA, N. \& FLETCHER, T. (2000b). Respiratory diseases in children and outdoor air pollution in Sao Paulo, Brazil: a time series analysis. Occup Environ Méd, 57, 477-83.

GOUVEIA, N., FREITAS, C. U., MARTINS, L. C., \& MARCILIO, I. O. (2006). Hospitalizações por causas respiratórias e cardiovasculares associadas à contaminação atmosférica no Município de São Paulo, Brasil. Cad. Saúde Pública, 22(12), 2669-2677.

GREGÓRIO, L. S. (2011). Risco ambiental à saúde humana: um estudo aplicado aos efeitos da poluição atmosférica no Estado do Rio de Janeiro. Dissertação (Mestrado em Geografia) - Universidade Federal do Rio de Janeiro, Rio de Janeiro.

INEA - Instituto Estadual do Ambiente. (2009). Relatório Anual de Qualidade do Ar. Rio de Janeiro: INEA.

INEA - Instituto Estadual do Ambiente. (2012). Notícia: CSA é multada em R $\$ 10,5$ milhões por nova "chuva de prata" em Santa
Cruz. Recuperado de: http://www.inea. rj.gov.br/Portal/Noticias/INEA_022233. Data 01/11/2012.

JACOBSON, B. S. (1984). The role of air pollution and other factors in local variations in general mortality and cancer mortality. Archives of Environmental Health, 3, 306-313.

\section{LEVY, D., GENT, M., \& NEWHOUSE,} M. T. (1977). Relationship between acute respiratory illness air pollution levels in an industrial city. American Review of Respiratory Diseases, 116, 167-173.

MAZUMDAR, S. \& SUSSMAN, N. (1983). Relationships of air pollution to health: Results from the Pittsburgh Study. Archives of Environmental Health, 38, 17 24.

OLIVEIRA, J. L. F. (2004). Análise espacial e modelagem atmosférica: contribuições ao gerenciamento da qualidade do ar da bacia aérea III da região metropolitana do Rio de Janeiro. Tese (Doutorado em Ciências Atmosféricas) COPPE - Universidade Federal do Rio de Janeiro, Rio de Janeiro.

OLIVEIRA, L. D. \& ROCHA, A. S. (2012). As Novas Dinâmicas Produtivas em curso na Baixada Fluminense: Breves apontamentos sobre uma nova Geografia da Indústria. Revista Pilares da História, Duque de Caxias, v. Ano 11, 7-13.

OSTRO, B., SANCHEZ, J. M., ARANDA, C., \& ESKELAND, G. S. (1996). Air pollution and mortality: results from a study of Santiago, Chile. J Expo Anal Environ Epidemiol, 6, 97-114.

PNUD - Programa das Nações Unidas para o Desenvolvimento. (2005). Relatório do Desenvolvimento Humano. Lisboa: Ana Paula Faria Editora. 
SALDIVA, P. H., POPE, C. A., SCHWARTZ，J., DOCKERY，D. W., LICHTENFELS, A. J., \& SALGE, J. (1995). Air pollution and mortality in elderly people: a time-series study in Sao Paulo, Brazil. Arch Environ Health, 50, 159-63.

SANTOS, A. M. S. P. (2003). Economia, espaço e sociedade no Rio de Janeiro. Rio de Janeiro: Editora FGV.
SCHIMMEL, H. \& MURAWSKI, T. J. (1976). The relation of air pollution to mortality. Journal of Occupation Medicine, 18, 316-333.

SOUZA, G. M. \& SANT'ANNA NETO, J. L. (2009). Geografia da saúde climatologia médica: ensaios sobre a relação clima e vulnerabilidade. (pp. 116-126). Hygeia: Revista Brasileira de Geografia Médica e da Saúde, Uberlândia. 